\title{
Preface: Implementing project management principles in geosciences
}

\author{
Luisa Cristini $^{1}$ and Sylvia Walter ${ }^{2}$ \\ ${ }^{1}$ Alfred Wegener Institute, Helmholtz Centre for Polar and Marine Research, Bremerhaven, Germany \\ ${ }^{2}$ Utrecht University, Faculty of Science, Institute for Marine and Atmospheric Research (IMAU) and Faculty of Geosciences, \\ Utrecht, the Netherlands
}

Correspondence: Luisa Cristini (luisa.cristini@awi.de)

Published: 9 April 2019

\begin{abstract}
Together with scientific creativity, good research project management is one of the keys for a successful project. This special issue compiles a collection of articles on several topics related to project management in Earth sciences. It is an initiating step towards building a body of literature in (geo)science project management in response to the need of research project managers to share their daily work, experiences and knowledge. It is composed of six original papers that present technical tools, interpersonal skills and focused areas of practice (ocean and polar sciences).
\end{abstract}

\section{Introduction}

The definition of projects - temporary organisational setups aiming to create a unique product or service within certain constraints such as time, costs and quality - allows a wide variety of interpretations of what a project actually is. In a scientific context, this could be an experimental setup, a data set, a methodology, or a published paper. It also includes collaborative research projects and programmes of international consortia with dozens of participants and stakeholders. Managing all these kinds of projects, independent from the consortium size, amount of funding or duration, means that the allocated resources should be spent to bring the project to a successful end, within the deadlines and the budget and delivering what was initially envisaged or developed over time. So an efficient and effective project management helps reduce waste of time and money.

Research projects and programs at both national and international levels are more and more challenged by an increasing requirement for interdisciplinarity, societal relevance, and educational outreach as well as market-oriented applications. They therefore need a clear management strategy, which is tailored to these demands and includes all aspects a research project can envisage in this context.

\subsection{Projects and project management}

Science projects are, as projects in any other sector, different from day-to-day operations and require a dedicated temporary structure, i.e., with a defined time frame. Projects also have a pre-defined scope and finite resources, and aim at producing a unique product, service or solution. They often include a team of people who have never worked together or don't usually collaborate.

Project management is, in a wider sense and according to the Project Management Institute ${ }^{1}$, the application of knowledge, skills, tools, and techniques to project activities to meet the project requirements. Project management entails a specific set of operations and tasks, designed to accomplish the defined objectives.

So what is project management for science? Science advances through projects, and projects are the very basis of scientific research. From master and doctoral thesis involving a handful of people to large international collaborations with hundreds of team members, academia is full of examples of projects. Oceanographic expeditions, fieldwork campaign, satellite missions for Earth observations, laboratory analysis, numerical modelling experiments are only few examples of the type of projects one can find in geosciences. For geoscientists as for any other scientist, project management is a tool

\footnotetext{
${ }^{1}$ https://www.pmi.org/pmbok-guide-standards/foundational/ pmbok (last access: 6 April 2019).
} 
that helps us carry out our research in an organised and sensible way to decrease the chances of errors and failure and increase the impact of our research. (Geo)science projects are most often international, interdisciplinary, intercultural and intersectoral and thus require tailored project management approaches.

\subsection{Challenges of research project management}

Research project management involves several challenges, which have the potential to jeopardize the project. Challenges can be external or internal to the project. External challenges include a variety of aspects that define the framework, but are not influenced directly by the consortium or the style of project management. Examples include the complexity of funding agencies' rules and regulations with respect to administrational, financial and legal aspects. Rules and regulations differ between project types and can change among the grants, which requires project managers to have a broad interdisciplinary and up-to-date knowledge of funding schemes, and high flexibility.

Internal challenges include those that originate within the consortium or project team or involve the project management approach. Examples of internal challenges are cultural differences (between countries, scientific disciplines, or societal sectors), quality assurance and data management, or the geographical distribution of the participating partners. A well thought-out project management plan developed during the proposal phase ensures not only a successful project but also a high value-for-money ratio.

\subsection{Motivation for this special issue on project management in geosciences}

Research project management is pervasive and becomes more and more required by funding agencies as integral part of research project proposals. Together with scientific creativity, good research project management is one of the keys for a successful project. Good management ensures a high impact and helps verify the responsible use of tax money within science.

Research project managers are scientists that contribute to a research project by managing the scientific work according to the funders' requirements and applying their knowledge of the tools and practices to ensure the scientific results are delivered according to plan. Research project managers therefore play a key role in the project team, especially in collaborative research projects and programmes of international consortia that demand a great deal of coordination, communication and negotiation skills.

However, research project management is still not implemented as a standard procedure in science and is often also not seen as part of successful research projects. In many contexts within science, in particular when it comes to training at the early stages of a scientific career, project man- agement is often considered a "soft skill", something that adds value to a curriculum, but not as essential as other more technical aspects of science (e.g., programming, laboratory methodologies, sampling or fieldwork). This needs a shift in the current cultural mindset and this shift is only possible if all science stakeholders, including project scientists, funding agencies representatives, organisation executives and project managers themselves, contribute.

Starting from these considerations on the role of research project managers and more widely project management in science, in 2014 we started a series of dedicated research project management sessions and workshops at the annual EGU General Assemblies, the largest geoscience conference in Europe. The EGU General Assembly was chosen as this conferences brings together geoscientists from all over the world to one meeting covering all disciplines of the Earth, planetary, and space sciences. Our aim was to bring together the scientists involved in research project management, with the objective to exchange knowledge and start up a network, which we felt still missing at that stage. Over the years the interest in the sessions and more widely the topic of project management increased so we decided to collect some of the contributions in a special issue.

This special issue is about implementing research project management principles in geosciences and compiles a collection of articles on several topics related to project management in Earth sciences. It should be seen as an initiating step towards building a body of literature in (geo)science project management in response to the need of research project managers to share their daily work, experiences and knowledge. There is currently a quite relevant body of literature on project management in business and administration, but very little in the science. Shared knowledge on research project management triggers improvement, increases the visibility of results and can thus significantly enhance the impact of science and research projects.

\section{Contributions to the special issue}

The special issue is composed of six original papers that present technical tools, interpersonal skills and focused areas of practice.

\subsection{Tools}

Koldunov and Cristini present an innovative way to apply a programming tool (Python) to automatise some repetitive tasks for retrieving, processing, analysing and synthesising various types of data. The application of this tool can be very helpful in managing large international projects with substantial data.

Wieters and Fritzsch discuss opportunities and limitations of software project management in geoscience and climate modelling examining version control systems and agile 
software development. They conclude that the exchange of knowledge and experience between geoscientists and software engineers should be promoted to overcome communication and cultural hurdles.

\subsection{Interpersonal skills/topics}

Schneider and Heinecke advocate for the importance of recognizing and accepting intercultural differences in the way science is understood and interpreted. They explore how science communication and science management can become more efficient and successful in terms of integrating local communities and non-scientific audiences.

Hoke et al. describe how a bottom-up association of European research institutions is organised and coordinated to help facilitate the development of climate change research, combining the capacities of national research institutions and inducing closer ties between existing national research initiatives, projects and infrastructures.

\subsection{Focused areas}

Barbier et al. highlight ethical values scientists should apply to ocean observations, which can be adopted as part of geoethics and the stewardship of the Earth system. The understanding of marine systems and environments is fundamental to managing human activities herein, and ocean observations particularly have an important role in enhancing the knowledge base of marine systems.

Werner et al. describe the main challenges of project management in polar sciences examining topics such as research infrastructures, interdisciplinary nature of polar sciences, international collaboration and polar community management. They present the results of a global survey that informed specific recommendations on the role of project and community managers for the advancement of frontier science.

\section{Conclusions}

This special issue is a first step towards building a body of reference literature in research project management. The articles show the critical role of research project managers in advancing geosciences, in particular as they support science and scientists, bridge communities, and coordinate efforts.

The special issue does not cover all aspects of project management as this topic is very wide and includes a diversity of issues. Rather it focuses of specific aspects (tools, interpersonal skills and specific areas of practice, such as ocean and polar sciences) to provide examples of the variety of challenges related with the management of research projects and of the opportunities for scientists to share knowledge and learn from their community. With this special issue we hope to have given the project managers in the geoscientific community an initial impulse to share their experiences and best practices and advance the field of project management in science.

Financial support. The article processing charges for this openaccess publication were covered by a Research Centre of the Helmholtz Association. 